\title{
AFIKSASI PEMBENTUK VERBA DALAM KARANGAN DESKRIPSI SISWA KELAS VII MTS MUHAMMADIYAH LEBUNG ITAM
}

\author{
Desti Mahareta, Zainal Abidin, Dessy Wardiah \\ destimahareta@gmail.com, zainalabidin@gmail.com,dessywardiah77@gmail.com \\ Universitas PGRI Palembang
}

\begin{abstract}
Abstrak: Masalah dalam penelitian ini menulis karangn deskripsi yang menganalisis afiksasi pembentuk verba dalam karangan deskripsi siswa VII MTs muhammadiyah lebung itam. Dalam pembelalaran bahasa Indonesia di kelas VII diarahkan untuk meningkatkan kemampuan siswa dalam membuat tulisan karangan deskripsi dalam bahasa Indonesia dengan baik dan benar, baik secara lisan maupun tulis,serta menumbuhkan apresiasi terhadap hasil karya sastra Indonesia. Tujuan penelitian untuk mendeskripsikan penggunaan afiksasi pembentuk verba dalam karangan deskripsi. Metode penelitian yang digunakan deskriptif kualitatif. Sumber data dalam penelitian ini adalah karangan deskripsi siswa kelas VII MTs Muhammadiyah Lebung Itam teknik pengumpulan data yang di gunakan teknik observasi dan dokumentasi. Tekniks analisis data yang digunakan yaitu analisis isi. Berdasarkan analisis data pembahasan tentang afiksasi pembentuk verba dalam karangan deskripsi dapat di simpulkan, pertama ditemukan 63 kata yang berafiks verba. Kedua terdapat siswa yang masih belum lengkap dalam menulis karangan deskripsi berdasarkan karangan.
\end{abstract}

Kata kunci: afiksasi verba, karangan deskripsi

\begin{abstract}
The problem in this research is to write a descriptive essay that analyzes the affixation of verbs in the descriptive essay of students of VII MTs muhammadiyah lebung itam. In learning Indonesian in class VII, it is directed to improve students' ability to write descriptive essays in Indonesian properly and correctly, both orally and in writing, and to foster an appreciation of Indonesian literary works. The purpose of the study was to describe the use of verb-forming affixation in descriptive essays. The research method used is descriptive qualitative. The source of the data in this study was a descriptive essay for class VII students of MTs Muhammadiyah Lebung Itam. The data collection techniques used were observation and documentation techniques. The data analysis technique used is content analysis. Based on the data analysis, the discussion about verb-forming affixation in descriptive essays can be concluded, firstly, 63 words with verb affixes were found. Second, there are students who are still incomplete in writing descriptive essays based on essays.
\end{abstract}

\section{Keywords: verb affixation, descriptive essay}

Artikel Diterima:22-05-2021 Artikel Disetujui:26-07-2021 Artikel Dipublikasi:20-08-2021

Corresponden Author: Desti Mahareta E-mail: destimahareta@gmail.com

DOI: http://dx.doi.org/10.31851/pembahsi.v11i12.6147

\section{PENDAHULUAN}

Bahasa merupakan alat

komununikasi yang kita pakai dalam

berinteraksi adalah sebuah sistem, artinya, bahasa

itu dibentuk oleh sejumlah

komponen yang berpola komponen 
secara tetap dan dapat dikaidahkan. Bahasa adalah suatu sistem lambang berupa bunyi, bersifat arbitrer, digunakan oleh suatu masyarakat tutur untuk bekerja sama, berkomunikasi, dan mengidentifikasi diri. Dari dua pendapat di atas dapat kita simpulkan bahwa bahasa adalah suatu komponen yang berpola secara tetap dan mempunyai sistem lambang berupa bunyi yang digunakan untuk mengekpresikan perasaan dan pikiran serta berfungsi sebagai alat komunikasi antar manusia.

Bahasa sangat dibutuhkan dalam berkomunikasi, sebagai alat komunikasi dalam kehidupan, oleh karena itu pembinaan dan pengembangan bahasa harus lebih ditingkatkan.Hal itu dapat dilakukan pada semua bidang bahasa yang dianggap tepat dan dapat menunjang kesempurnaan bahasa Indonesia. Pada bidang morfologi misalnya, pembinaan dan pengembangan biasanya diarahakan pada proses pembentukan kata (Fitriani, 2019). Proses pembentukan kata tersebut dapat dilakukan dengan cara pembubuhan afiks atau afiksasi, pemajemukan, dan pengulangan atau reduplikasi.

Proses pembubuhan melalui afiksasi atau pembubuhan afiks pada umumnya sangat berpotensi mengubah makna dan bentuk kata. Sebagai contoh: dapat dilihat pada kata kerja (verba) seperti tempur, kelahi, dan minum. Pembubuhan afiks pada kata-kata itu akan menghasilkan kata bertempur, berkelahi dan meminum. Jadi, proses afiks atau afiksasi sangat penting dan memerlukan ketepatan karena jika salah maka makna dan bentuknya akan menjadi tidak sempurna. Kata kata yang dapat dibubuhi imbuhan tidak hanya kata kerja (verba), tetapi juga kata benda (nomina), kata sifat (adjektiva), kata keterangan (adverbial), dan kata bilangan ( numerilia), akan tetapi pembahasan penelitian hanya dititikberatkan pada afiksasi dalam kata kerja (verba).

Arifin, (2007) menjelaskan Afiksasi adalah "proses morfologis yang mengubah sebuah leksem menjadi kata setelah mendapat afiks, yang dalam bahasa kita cukup banyak". Chaer (2016) Proses afiksasi adalah "proses pembubuhan afiks pada bentuk dasar, baik dalam membentuk verba tururnan, nomina turunan, maupun kategori turunan lainya". Mulae \& Sarif, (2021)kata verba adalah kata yang menggambarkan aksi atau keadaan”.

\section{Hakikat Kata}

Istilah kata sering kita dengar dan sering kita gunakan. Mungkin barangkali kata kata ini hampir setiap hari dan setiap saat selalu kita gunakan dalam segala kesempatan dan untuk segala keperluan.Namun kalau ditanya apakah kata itu?Maka 
jawabnya barangkali tidak semudah menggunakan. Para linguis yang sehari-hari bergelut dengan kata ini, hingga dewasa ini, kiranya tidak mempunyai kesamaan pendapat mengenai konsep apa yang disebut kata itu.

Para tata bahasawan tradisional biasanya memberi pengertian terhadap kata berdasarkan arti dan ortografi.Menurut mereka kata adalah satuan bahasa yang memiliki satu pengertian; atau kata adalah deretan huruf yang diapit oleh dua buah spasi, dan mempunyai satu arti. Kata "adalah satuan grmatikal bebas terkecil. Dengan kata lain, kata mempunyai kemampuan untuk berdiri sendiri sebagai kalimat terlengkap misalnya sebagai jawaban singkat atau sebagai kalimat seruhan"(Missriani \& Fitriani, 2020).

Jadi dapat kita simpulkan bahwa kata adalah satuan bahasa yang memiliki satu pengertian yang dapat berdiri sendiri. Dari uraian di atas dapat penulis simpulkan bahwa dengan adanya proses morfologis maka akan terbentuk kata. suatu proses pembentukan kata dengan cara menghubungkan satu morfem dengan morfem lain atau proses yang mengubah leksem menjadi sebuah kata (Heru, 2018).

\section{Kata Kerja (verba)}

Waridah (2008) menjelaskan
Kata kerja adalah "kata yang
menyatakan makna perbuatan,
pekerjaan, tindakan, proses, atau

keadaan". Abdul (2003) menjelaskan kata kerja adalah "kata yang diikuti oleh frase dengan..., baik yang menyatakan alat, yang menyatakan keadaan, mapun yang menyatakan penyert. (Kridalaksana, 1986)Kata kerja adalah "kata yang pada umumnya menyandang fungsi predikat, didahului unsur yang berfungsi sebagai subjek diikuti oleh objek atau pelengkap; dapat didahului kata seperti sedang, sudah, dan tidak; dapat didahului kata seperti silakan atau tolong; dan mengungkapkan makna 'tindakan', 'proses', atau 'keadaan'”.

Jadi menurut pendapat di atas penulis dapat menyimpulkan bahwa kata kerja adalah kata yang menggambarkan aksi atau perbuatan dan biasanya menyandang fungsi predikat di dalam sebuah kalimat.Adapun ciri-ciri kata kerja sebagai berikut.

a.umumnya menempati fungsi predikat dalam kalimat

Contoh:

Grup band ungumembuatalbum baru $\begin{array}{lll}\mathrm{S} & \mathrm{P} & \mathrm{O}\end{array}$

b.dapat didahului kata keterangan akan, sedang, dan sudah.

Contoh:

Yasminsedang menontontelevisi

$$
\begin{array}{lll}
\mathrm{S} & \mathrm{P} & \mathrm{O}
\end{array}
$$

c. dapat didahului kata ingkar tidak.

Pintu initidak dikuncisejak tadi malam.

$\mathrm{S} \quad \mathrm{P} \quad$ Ket


d.dapat dipakai dalam kalimat perintah, khususnya yang bermakna perbuatan.

Contoh:

Makan obat ini

e. tidak dapat didahului kata paling.

Contoh:

Paling datang (?)

Mulyono (2013)“Kemudian jenis verba dapat diklasifikasikan berdasarkan jenisnya(perilaku sintaksis) dan berdasarkan bentuknya ( perilakumorfologis)". Berdasarkan jenisnya dikenal adanya verba intransitif, transitif. Kridalaksana (1986) menjelaskan "verba transitif adalah verba bisa mempunyai atau harus mendampingi obyek". Mulyono (2013) juga berpendapat bahwa verba intransitif adalah"verba yang menghindarkan obyek atau tidak memerlukan obyek".

\section{Afiksasi Pembentuk Verba}

Arifin (2007)Afiksasi atau imbuhan adalah proses morfologis yang mengubah sebuah leksem menjadi kata setelah mendapat afiks, yang dalam bahasa kita cukup banyak jumlanhnya. Dapat di simpulkan dari pendapat di atas dalam bukunya ada 10 afiks pembentukan verba, yaitu sebagai berikut:

1. Verba berprefiks ber-

$$
\text { Makna gramatikal }
$$
berafiks ber- 'berisi' atau 'mengandung' apabila bentuk dasarnya memiliki komponen makna ( + benda), ( + dalaman), atau ( + kandungan). Contoh: berkuman 'mengandung kuman' berair 'berisi air' berpenyakit 'mengandung penyakit,. Makna gramtikal 'mengeluarkan' atau 'menghasilkan' apabila bentuk dasarnya memiliki komponen makna ( + benda), ( + hasil) atau ( + keluar). Contoh: berproduksi 'menghasilkan produksi' bertelur 'mengeluarkan telur' berair mata 'mengeluarkan air mata'. Makna gramtikal 'mengusahakan' atau 'mengupayakan'apabila bentuk dasarnya memiliki komponen makna ( + bidang usaha). Contoh: berternak 'mengusahakan ternak' berladang 'mengusahakan ladang'.

Makna gramatikal
'kumpulan' atau 'kelompok' apabila bentuk dasarnya memiliki komponen makna $(+$ jumlah $)$ atau ( + hitungan). Contoh: bertiga 'kumpulan dari tiga (orang) berempat 'kumpulan dari empat (orang). Makna gramatikal 'memberi' apabila bentuk dasarnya memiliki komponen makna ( + benda) dan ( + berian). Contoh: berceramah 'memberi ceramah' berkhotbah 'memberi khotbah'.

2. Verba berkonfiks dan berklofiks ber-an

Verba berbentuk ber-an deperti pada kata bermunculan dan berpakaian memiliki dua 
macam proses pembentukan. Pertama, yang berupa konfiks, artinya prefiks ber- dan sufiks an itu diimbuhkan secara bersamaan sekaligus pada sebuah dasar.Kedua yang berupa klofiks artinya prefiks ber-dan sufiks - an itu tidak diimbuhkan secara bersamaan pada sebuah dasar.

Ber-an sebagai konfiks memiliki satu makna, sedangkan ber-an sebagai klofiks memiliki makna yang terpisah. Makna gramatikal verba berkonfiks beran adalah 'banyak serta tidak teratur' apabila bentuk dasarnya memiliki komponen makna $(+$ tindakan), ( + sasaran) dan ( + gerak). Contohnya: berlarian 'banyak yang berlari dan tidak teratur' bermunculan 'banyak yang muncul dan tidak teratur'. Makna gramatikal 'saling' atau 'berbalasan' apabila bentuk dasarnya memiliki komponen makna ( + tindakan), ( + sasaran) dan ( + gerak $)$. Contohnya: bersentuhan 'saling bersentuhan' bertangisan 'saling bertangisan'.

Kemudian, makna gramatikal 'saling berada di' apabila bentuk dasarnya memiliki komponen makna ( + benda), $(+$ letak) dan ( + tempat). Contoh: bersebalahan 'saling berada diseblah' berhadapan' saling berada di hadapan.

3. Klofiks ber-kan
Verba berklofiks ber-kan dibentuk dengan proses, mulamula kepada bentuk dasar diimbuhkan prefiks ber-, lali diimbuhkan pula sufiks -kan. Contoh: bersenjata diimbuhkan pula sufiks-kan sehingga menjadi bersenjatakan

4. Verba bersufiks -kan

Makna gramatikal
'jadikan berada di' apabila
bentuk dasarnya memiliki
komponen makna ( + tempat)
atau ( + arah). Contoh:
pinggirkan 'jadikan berada di
pinggir' ketengahkan 'jadikan
berada di tangah'. Memilki
makna gramatikal 'lakukan
untuk orang lain' apabila
dasarnya memiliki komponen
makna ( + tindakan) dan ( +
sasaran). Contoh: bukakan'
lakukan buka untuk (orang lain)
ambilkan ( lakukan ambil untuk
(orang lain). Makna gramatikal
'lakukan akan' apabila bentuk
dasarnya memilki komponen
makna ( + tindakan) dan ( +
sasaran). Contoh: lemparkan'
lakukan lempar akan' hindarkan
'lakukan hinder akan'. Memiliki
makna gramatikal 'bawa masuk
ke' apabila bentuk dasarnya
memilki komponen makna ( +
ruang). Contoh gudangkan
'bawa masuk ke gudang'
rumahkan 'bawa masuk ke
rumah'.
(a)

5. Verba berSufiks $-i$ 
Verba bersufiks- $i$ adalah verba transitif, yang berlaku juga sebagai pangkal (stem) dalam pembentukan verba inflektif. Verba bersufiks- $I$ memilki makna gramatikal 'berulang kali' apabila bentuk dasarnya memilki komponen makna ( + tindakan) dan ( + sasaran). Contoh: pukuli 'pekerjaan pukul dilakukan berualng kali' potongi ${ }^{\text {' }}$ pekerjaan potong dilakukan berualng kali'. Makna gramatikal tempal apabila bentuk dasarnya mempunyai komponen makna ( + tempat). Contoh: duduki' duduk di...' Lompati ' lakukan lompat di...'. Makna gramatikal 'merasa sesuatu pada' apabila bentuk dasarnya mempunyai komponen makna ( + sikap batin) atau ( + emosi). Contoh: takuti ' merasa takut pada' hormati 'merasa hormat pada'.

6. Verba berkonfiks pe-kan

Verba berkonfiks per-kan adalah verba yang bisa menjadi pangkal dalam pembentukan verba inflektif (berprefiks me-, berprefiks $d i$ - atau berprefiks ter-). Verba berkonfiks per-kan memiliki makna gramatikal 'jadikan bahan per-kan' apabila bentuk dasarnya memiliki komponen makna ( + kegiatan). Contoh: perdebatkan 'jadikan bahan debat' pertanyakan 'jadikan bahan pertanyaan'.
Kemudian memilki makna gramatikal 'lakukan supaya (dasar)' apabila bentuk dasarnya memiliki komponen makna ( + keadaan).

Contoh: persamakan' lakukan supaya sama' pertegaskan 'lakukan supaya tegas'.

7. Verba berkonfiks per-i

Verba berkonfiks per- $i$ adalah verba yang dapat menjadi pangkal dalam pembentukan verba inflektif (berprefiks $m e$ - inflektif, $d i$ - atau ter- inflektif). Verba berkonfiks per-i memilki makna gramatikal 'lakukakan supaya jadi' apabila bentuk dasarnya memiliki komponen makna ( + keadaan). Contoh: perlengkapi 'lakukan supaya jadi lengkap' perbaiki 'lakukan supaya jadi baik'. Selanjutnya memiliki makna gramatikal 'lakukan (dasar) pada objeknya' apabila bentuk dasarnya memiliki komponen makna ( + tindakan) dan ( + lokasi). Contoh: perturuti 'lakukan turut pada objeknya' pergauli 'lakukan gaul pada objeknya'.

8. Verba berprefiksme-

Verba berprefiks medapat berbentuk me-, mem-, meny-, meng-, dan menge-,. Bentuk atau alomorf medigunakan apabila bentuk dasarnya dimulai dengan fonem $r, l, y, m, n, n y$, dan ng. contoh: memerah, melongok, menanti, 
meyakini, mewarisi, mengerikan. Bentuk alomorf mem- digunakan apabila bentuk dasarnya dimulai dengan fonem $b, p, f$, dan $v$. dengan catatan fonem $b$, f, dan $v$ tetap terwujud, sedangkan fonem $p$ tidak diwujudkan, melainkan disenyawakan dengan bunyi nasal dari prefiks itu . contoh: membina, memfitnah, memotong.

Bentuk men- digunakan apabila bentuk dasarnya dimulai dengan fonem $d$ dan $t$ dengan catatan fonem $d$ tetap tetap terwujudkan sedangkan fonem $t$ tidak diwujudkan melainkan disenyawakan dengan bunyi nasal yang ada pada prefiks tersebut. Contoh: mendidik, menduda, menerobos.

Bentuk meny- digunakam apabila fonem awal bentuk dasarnya adalah fonem $c, j$,dans. bunyi ny pada prefiks diganti atau dituliskan dengan huruf $n$ pada dasar dengan fonem $c$ dan $j$, sedangkan yang mulai dengan fonem $s, \quad$ fonem $s$-nya diluluhkan. Contoh: mencicil (lafalnya:menycicil) menjual (lafalnya : menyjual).

9. Verba berprefiks ke-

Verba berprefiks $k e$ digunakan dalam bahasa ragam tidak baku. Fungsi dan makna gramatikalnya sepadan dengan verba berprefiks ter-.Ketipu sepadan dengan tertipu,kebawa sepadan dengan terbawa.

10. Konfiks ke-an

Perlu diketahui ada dua macam konfiks ke-an, yaitu konfiks ke-an membentuk verba dan konfiks ke-an yang membentuk nomina. Verba berkonfiks ke-an termasuk verba pasif, yang tidak dapat dikembalikan kedalam verba aktif, seperti verba pasif $d i$ - dan dan verba pasif ter-. Verba berkonfiks ke-an memiliki makna gramatikal 'terkena, menderita, mengalami (dasar)' apabila bentuk dasar memiliki komponen makna $(+$ peristiwa alam) atau ( + hal yang tidak enak). Contoh: kebakaran 'menderita bakar' kehausan 'menderita haus'.

Kemudian, verba berkonfiks ke-an memiliki makna gramatikal 'agak (dasa)' apabila bentuk dasarnya memilki komponen makna ( + warna). Contoh: kemerehan 'agak merah' kekuningan 'agak kuning'

\section{METODOLOGI}

Penelitian ini menggunakan metode kualitatif, Muhammad (2011) menjelaskan pendekatan kualitatif "adalah penelitian yang menghasilkan data deskriptif berupa kata-kata tertulis atau lisan dari orang-orang dan perilaku yang dapat 
diamati”. Dalam penelitian ini yang dijadikan objek penelitian yaitu karangan deskripsi siswa kelas VII di MTs. Muhammadiyah Lebung Itam.Tujuan dari penelitian ini adalah untuk mendeskripsikan penggunaan afiksasi pembentuk verba dalam karangan deskripsi siswa

Dalam penelitian melakukan dengan memberikan karangan pada murid. Data di ambil hanya beberapa siswa yang ada di kelas MTs. Muhammdiyah Lebung Itam untuk dianalisis berdasarkan pertimbangan banyaknya penggunaan afiksasi verba di dalam data tersebut. Data tersebut dianalisis menggunakan teori afiksasi pembentu verba. Hal ini dilakukan karena data yang diperoleh berupa karangan yang berbentuk karangan deskripsi dengan tema yang tidak di tentukan. Peneliti mengklasifikasikan data, menganalisis data, dan menarik kesimpulan sesuai hasil yang telah dilakukan. Data tersebut dianalisis menggunakan teori, afiksasi pembentuk verba dalam karangan deskripsi. Hal ini dilakukan karena data yang diperoleh berupa teks yang berbentuk karangan deskripsi dengan tema yang tidak menentukan.

Adapun analisis datanya sebagai berikut:

1) Afiksasi pembentuk verba

a) Peneliti membaca hasil karangan deskripsi yang dibuat oleh siswa. b) Peneliti mengklasifikasiskan katakata dalam bentuk table.

c) Kata berafiksasi ditulis dengan huruf miring untuk kejelasan data dalam karangan deskripsi siswa.

\section{HASIL DAN PEMBAHASAN}

Dari hasil hasil observasi penulis pada siswa kelas VII /B MTs Muhammadiyah Lebung Itam yang berjumlah 22 0rang, namun peneliti hanya mengambil data berupa 10 karangan deskripsi yang dibuat oleh siswa, karangan deskripsi tersebut dibuat dengan judul yang tidak ditentukan.

Berikut 10 teks berita siswa tersebut:

\section{1. ruang kelas wina}

Wina membuka pintu kelasnya perlahan-lahan. Dilihatnya sebuah jendela yang terbuka. Di bawah jendela, tampak sebuah meja guru yang memakai telapak putih. Di atas taplak putih itu ada vas bunga dari kayu.

Vas bunga tersebut bergambar beberapa kuntum bunga matahari seperti bunga yang ada didalamnya. Disebelahnya tergeletak sebuah agenda kelas yang terbuka dan kalender duduk.

Wina lalu memasuki ruang kelasnya dengan langkah yang lambat. Dia memalingkan pangdangan yang lambat ke arah 
kanan. Tampak satu buah white board yang bersih tanpa coretan.

\section{2. jalan-jalan ke pasar}

Hari ini adalah hari minggu, jadi pagi-pagi aku nggak usah berangkat ke sekolah. Aku dan mama berencana untuk memasak masakan favoritku yaitu capcai. Untuk mendapatkan bahan-bahannya kami harus kepasar pagi, dan aku berencana ikut mama ke pasar pagi.

Pasar pagi di daerah tempat aku tinggal terletak di pinggir pelabuhan, untuk menuju kesana membeutuhkan waktu lima menit menggunakan kendaraan bermotor, pagi-pagi pukul tujuh, aku dan mama berangkat kepasar pagi menggunakan sepeda motor.

\section{Keindahan alam indonesiaku}

Indonesia merupakan Negara yang memiliki penduduk terbanyak ke empat setelah china,india dan amerika dan Indonesia merupakan Negara dengan kekayaan alam yang melimpah rua dari sabang sampai marauke. Keindahan alam Indonesia memang di anggap tak ada tandingan nya di Negara mamnapun di dunia.

Hampir semua alam yang berada di Indonesia dari darat sampai lautan. Maka dari itu tak heran jika banyak para wisatawan asing rela berkunjung ke Indonesia untuk melihat keindahan alamnya.

Selain itu juga keindahan yang disajikan ternyata di dalamnya terdapat banyak hal tersembunyi yang bisa jarang kita lihat atau kita jumpai seperti flora dan fauna.

\section{Rumahku}

Rumahku adalah rumah munggil di depan mushola. Rumah itu mempunyai luas sekitar 36 meter persegi. Dengan warna cat hijau muda membuat rumah itu terlihat sejuk dipandang mata. Halamam sempit di depan reumah penuh dengan tanaman yang ditanam di pipa. Setiap tanaman tumbuh subur, bahkan tanaman cabe sudah berbuah banyak.

Rumahku terdiri dari 1 ruang tamu, 1 kamar tidur, 1 ruang santai, dapur, dan 1 kamar mandi. Di ruang tamu hanya berisi karpet sebagai alas duduk rak buku yang terpasang di dinding. Agar suasana harum ada pewangi semprot otomatis yang terpasang di dinding. Semua barang yang ada di rumah selalu terata rapi. Lantai keramik berwarna putih membuat rumah mungil ini menjadi Nampak luas.

\section{Pantai}

Salah satu tempat yang saya sukai ketika berlibur adalah pantai. Hal yang membuat saya menyukai pantai kerena suasana di sana, apalagi ketika sore hari. Pemandangan sore dipantai sangat indah.

Ombaknya yang menabrak dipadukan dengan mataharu yang sedang terbenam. Orang-orang yang tertawa dan bermain di bawah 
matahari terbenam. Butiran pasir menyentuh kaki perlahan melalui jari-jari ketika berjalan sepanjang garis pantai.

Tak hanya itu, awan putih dilangit juga turut menambah suasana di pantai semakin menentramkan. Kicauan burung seperti sedang mendengdangkan lagu. Semilir anginnya yang berhembus rambut menambah kesejukan pantai.

\section{Kebakaran}

Peristiwa menyedihkan ini terjadi kebakaran di sebuah rumah kos yang berada di pusat kota tarakan. Wilayah ini memang sangat terkenal keramaiannya karena menjadi pusat rumah kos yang ada di tarakan.

Saat itu adalah weekend,beberapa teman kos sudah pulang ke rumah masing-masing. Hanya ada aku dan beberapa orang saja. Bahkan pemilik kos juga sedang berlibur ke luar kota.

Kejadian ini terjadi pada sore hari. Saat itu aku baru selesai mencuci baju dan ingin tidur. Sebelum tidur aku terlebih dahulu mengecas handphone kemudian aku tertidur agar ketika bangun baterai handphone sudah penuh namun yang terjadi di luar dugaan stop kontak aku konslet dan akhirnya terjadi kebakaran di kosan aku.

\section{Jam tangan}

Jam tangan merupakan suatu aksesoris yang dipakai pada pergelangan tangan, sama halnya seperti memakai gelang tangan. Namun aksesoris jam tangan satu ini lebih jauh efektif serta fugsional. Tak hanya itu saja, jam tangan juga bisa dipakai sebagai alat pendukung penampilan.

\section{Gunung bromo}

Bromo dikenal sebagai salah satu tempat wisata utama di jawa timur. Tempat ini terletak di taman nasional bromo tengger semeru, di sebelah timur kota malang. Keindahan gunung ini telah menarik banyak pengunjung dari berbagai Negara di dunia.

Menyaksikan matahari terbit adalah peristiwa yang menarik . para pengunjung dari berbagai rela menunggu mulai pukul 05.00 agar tidak kehilangan momen special ini.

Ketika langit cerah anda bisa melihat bola matahari. Pertama, matahari terlihat seperti korek api, perlahan-lahan memperbesar sampai membentuk lingkaran penuh dan mencerahkan. Pemandangan yang sangat indah.

\section{Hasil Analisis Data}

1) Bentuk analisis Pada karangan deskripsi Ke 1

a. Analisis Afiksasi Pembentuk Verba

(1). Pada teks karangan deskripsi ke 1 Terdapat Tujuh Afiksasi Pembentuk Verba Yaitu:

Tabel 4.4 Kata Berafiks Verba membuka $=$ membuka sesuatu 


\begin{tabular}{|l|}
\hline (jendela) \\
\hline perlahan-lahan = pelan-pelan \\
\hline dilihatnya = sedang melihat \\
\hline terbuka= sedang mebuka jendela \\
\hline $\begin{array}{l}\text { Bercoretan= tidak ada coretan } \\
\text { (bersih) }\end{array}$ \\
\hline bergambar = seperti hiasan \\
\hline disebelahnya = bersampingan \\
\hline
\end{tabular}

2) Bentuk Analisis Data Pada karangan deskripsi Ke 2

a. Analisis Afiksasi Pembentuk Verba

(1) Pada karangna deskripsi ke 2 Terdapat Sembilan Afiksasi

Pembentuk Verba Yaitu:

Tabel 4.5 Kata Berafiks Verba

\begin{tabular}{|l|}
\hline Berangkat = beranjak (pergi) \\
\hline Berencana = merencang sesuatu \\
\hline Memasak = membuat makanan \\
\hline $\begin{array}{l}\text { Mendapatkan = sedang } \\
\text { memperoleh }\end{array}$ \\
\hline Terletak = sudah di tempatkan \\
\hline Menuju = mengenakan tuju kepada \\
\hline $\begin{array}{l}\text { membutuhkan = menginginkan } \\
\text { sesuatu }\end{array}$ \\
\hline menggunakan = sedang memakai \\
\hline bermotor = sedang mengendarai \\
\hline
\end{tabular}

3) Bentuk Analisis Pada karangan deskripsi Ke 3

a. Analisis Afiksasi Pembentuk Verba

(1) Pada karangan deskripsi Ke 3 Terdapat Duabelas Afiksasi

Pembentuk Verba Yaitu:

Tabel 4.6 Kata Berafiks Verba

\begin{tabular}{l} 
merupakan $=$ telah membuat \\
\hline Memiliki $=$ sedang mempunyai
\end{tabular}

\begin{tabular}{|l|}
\hline (sesuatu) \\
\hline Penduduk = warga setempat \\
\hline Terbanyak = sesuatu yang teramai \\
\hline Kekaya $\boldsymbol{a n}$ = sesuatu aset ( harta) \\
\hline Melimpah = telah meluap (penuh ) \\
\hline Keindahan = sesuatu yang cantik \\
\hline $\begin{array}{l}\text { Berada = dalam keadan ada (di } \\
\text { tempat) }\end{array}$ \\
\hline $\begin{array}{l}\text { Berkunjung = sedang mengunjungi } \\
\text { tempat }\end{array}$ \\
\hline Disajikan = telah menyediakan \\
\hline $\begin{array}{l}\text { Terdapat = sedang mendapatkan }( \\
\text { sesuatu) }\end{array}$ \\
\hline Tersembunyi = tidak terlihat \\
\hline
\end{tabular}

4) Bentuk Analisis Data Pada karangan deskripsi Ke 4

a. Analisis Afiksasi Pembentuk Verba

(1) Pada karangan deskripsi ke 4 Terdapat Lima Afiksasi Pembentuk Verba Yaitu:

Tabel 4.7 Kata Berafiks Verba

\begin{tabular}{|l|}
\hline Mem punyai = sudah memiliki \\
\hline $\begin{array}{l}\text { Mem } \text { buat = sedang dalam proses } \\
\text { buat }\end{array}$ \\
\hline Terdiri = telah terwujudnya \\
\hline Terpasang = sedang memasangkan \\
\hline Berwarna = mempunyai warna \\
\hline
\end{tabular}

5) Bentuk Analisis Pada karangan deskripsi ke 5

a. Analisis Afiksasi Pembentuk Verba

(1) Pada karangan deskripsi ke 5 Terdapat Sepuluh Afiksasi Pembentuk Verba Yaitu:

Tabel 4.8 Kata Berafiks Verba 


\begin{tabular}{|c|}
\hline Suka $i=$ telah menyukai \\
\hline $\begin{array}{l}\text { berlibur }=\text { sedang melakukan } \\
\text { berpiknik }\end{array}$ \\
\hline $\begin{array}{l}\text { Pemandangan }=\text { sedang melihat } \\
\text { (alam) }\end{array}$ \\
\hline $\begin{array}{l}\text { Menabrak = dalam keadaan } \\
\text { menabrak sesuatu }\end{array}$ \\
\hline $\begin{array}{l}\text { Dipadukan= telah mencocokan } \\
\text { sesuatu }\end{array}$ \\
\hline Terbenam = telah menghilang \\
\hline tertawa = sedang berbahagia \\
\hline $\begin{array}{l}\text { Bermain }=\text { melakukan sesuatu } \\
\text { untuk bersenang senang }\end{array}$ \\
\hline $\begin{array}{l}\text { Perlahan }=\text { melakukan dengan } \\
\text { pelan }\end{array}$ \\
\hline $\begin{array}{l}\text { Berjalan }=\text { melangkah kaki } \\
\text { bergerak maju }\end{array}$ \\
\hline
\end{tabular}

6) Bentuk Analisis Pada Karangan Deskripsi Ke 6

a. Analisis afiksasi pembentuk verba

(1) Pada Karangan Deskripsi Ke 6 Terdapat Sembilan Afiksasi Pembentuk Verba Yaitu:

Tabel 4.9 Kata Berafiks Verba

\begin{tabular}{|l|}
\hline terjadi = telah terjadi (diadakan) \\
\hline $\begin{array}{l}\text { Menyedihkan = telah terjadih } \\
\text { kesedihan (menangis) }\end{array}$ \\
\hline $\begin{array}{l}\text { Berada = dalam keadaan ada } \\
\text { (tempat) }\end{array}$ \\
\hline $\begin{array}{l}\text { Terkenal = sudah dikenal banyak } \\
\text { orang }\end{array}$ \\
\hline Keramaian = telah terjadi keramaian \\
\hline Menjadi = telah terjadi \\
\hline Beberapa = telah adanya sebagian \\
\hline
\end{tabular}

Berlibur = sedang malukan piknik

Mencuci $=$ sedang mencuci (baju)

7) Bentuk Analisis Pada Karangan Deskripsi ke 7

a. Analisis Afiksasi Pembentuk Verba

(1) Pada Karangan Deskripsi Ke 7 Terdapat Enam Afiksasi Pembentuk Verba Yaitu:

Tabel 4.10 Kata Berafiks Verba

\begin{tabular}{|l|}
\hline $\begin{array}{l}\text { dipakai = sedang menggenakan } \\
\text { (sesuatu) }\end{array}$ \\
\hline $\begin{array}{l}\text { Memakai = sedang menggenakan } \\
\text { (sesuatu) }\end{array}$ \\
\hline $\begin{array}{l}\text { Penampilan = dalam keadaan } \\
\text { berpakaian (fashion) }\end{array}$ \\
\hline Pengikat = telah di ikat \\
\hline $\begin{array}{l}\text { Terdiri = telah berdiri hasilnya } \\
\text { (sesuatu) }\end{array}$ \\
\hline $\begin{array}{l}\text { Memiliki = telah mempumyai } \\
\text { (sesuatu) }\end{array}$ \\
\hline
\end{tabular}

8) Bentuk Analisis Pada Karangan Deskripsi Ke 8

a. Analisis Afiksasi Pembentuk Verba

(1) Pada Karangan Deskripsi Ke 8 Terdapat Sebelas Afiksasi Pembentuk Verba Yaitu:

Tabel 4.11 Kata Berafiks Verba

\begin{tabular}{|l|}
\hline Dikenal = sudah dikenal \\
\hline Terletak= sudah di tempatkan \\
\hline Ke indahan= sesuati yang cantik \\
\hline Menarik = telah menjadi sesuatu \\
yang disukai \\
\hline Pengunjung = sedang melakukan \\
\hline
\end{tabular}




\begin{tabular}{|l|}
\hline kunjungan \\
\hline $\begin{array}{l}\text { Menyaksikan = telah terjadinya } \\
\text { melihat (sesuatu) }\end{array}$ \\
\hline Pertama = yang awal \\
\hline $\begin{array}{l}\text { Menunggu = sedang mengharap } \\
\text { sesuatu akan terjadi (datang) }\end{array}$ \\
\hline Perlahan-lahan = harus pelan-pelan \\
\hline $\begin{array}{l}\text { Membentuk = sedang dalam proses } \\
\text { bentuk }\end{array}$ \\
\hline $\begin{array}{l}\text { Memperbesar = sesuatu yang } \\
\text { membesar (benda) }\end{array}$ \\
\hline
\end{tabular}

Berdasarkan hasil penelitian di atas, pada karangan deskripsi siswa kelas VII B MTs. Muhammadiyah Lebung Itam Kecamatan Tulung Selapan Kabupaten Ogan Komering Ilir. Dari 10 data yang di ambil terdapat katakata yang mengandung afiksasi pembentuk verba, dan terdapat siswa yang belum lengkap dalam menulis karangan deskripsi . Afiksasi pembentuk verba merupakan salah satu proses dalam pembentukan kata turunan baik berkategori verba, berkategori nomina maupun berkategori ajektiva. Namun dalam penelitian ini hanya membahas tentang afiksasi berkategori verba dalam karangan deskripsi yang dibuat siswa kelas VII B MTs. Muhammadiyah Lebung Itam. Dari hasil analisis peneliti terhadap karangan deskripsi yang dibuat oleh siswa kelas VII B MTs. Muhammadiyah Lebung Itam terdapat ditemukan 63 kata yang berafiks verba. yang terdiri dari 21 prefiks me-, 14 prefiks ber-, 12 prefiks ter-, 5 prefiks $d i$-, 2 prefiks per-, 5 konfiks ke-an, 2 konfiks pean, 1 sufiks -kan, 1 sufiks $-i$.

Afiksasi verba berprefiks terpada karangan deskripsi siswa kelas VII B MTs. Muhammadiyah Lebung Itam, terdapat pada kata terjadi, terletak, tercermin, terbuka, terbanyak, terdapat, tersembunyi, terpasang, terdiri, terbenam, tertawa, terkenal,

Afiksasi verba berprefiks $m e$ pada karangan deskripsi kelas VII B MTs. Muhammadiyah Lebung Itam, terdapat pada kata: memiliki, menerus, melompat, menarik, menyaksikan, membutuhkan, menuju, memakai, memasak, membuat, membesar, melihat, menunggu, mendapat, menuju, menggunakan, melimpah, mempunyai, membuka, menabrak, menjadi, mencuci, merupakan.

Afiksasi verba berprefiks terpada karangan deskripsi kelas VII B MTs. Muhammadiyah Lebung Itam terdapat pada kata: terjadi, tercermin, terbenam, terkenal, terletak, terdiri, tertawa, terpasang, terbanyak, terdapat, tersembunyi

Afiksasi verba berprefiks berpada karangan deskripsi kelas VII B MTs. Muhammadiyah Lebung Itam terdapat pada kata: berbulu, bergerak, berlibur, beberapa, berhenti, berada, berkunjung, berwarna, bermotor, berjalan, bermain, berencana, berangkat, bergambar. 
Afiksasi verba berprefiks $d i$ pada karangan deskripsi siswa kelas VII B MTs. Muhammadiyah Lebung Itam terdapat pada kata: dikenal, dipakai, disajikan, dilihatnya, disebelahnya.

Afiksasi verba berkonfiks $k e$ an pada karangan deskripsi siswa kelas VII B MTs. Muhammadiyah Lebung Itam terdapat pada kata: keragaman, kepulauan, keindahan, keramaian, kekayaan.

Afiksasi verba berkonfiks pean pada karangan deskripsi siswa kelas VII B MTs. Muhammadiyah Lebung Itam terdapat pada kata: penampilan, pemandangan.

Afiksasi verba bersufiks $-k a n$ pada karangan deskripsi siswa kelas VII B MTs. Muhammadiyah Lebung Itam terdapat pada kata: dapatkan

Afiksasi verba bersufiks $-i$ pada teks karangan deskripsi kelas VII B MTs. Muhammadiyah Lebung Itam terdapat pada kata: sukai.

Afiksasi verba berprefiks per teks karangan deskripsi kelas VII B MTs. Muhammdiyah Lebung Itam terdapat pada kata: perlahan-lahan, pertama.

Berdasarkan dua hasil penelitian diatas tentang afiksasi pembentuk verba dalam karangan deskripsi siswa kelas VII B MTs. Muhammadiyah Lebung Itam bahwa penggunaan afiksasi dalam kegiatan hal menulis sangat di perlukan karena untuk membentuk sebuah kata agar kata tersebut mudah di mengerti oleh orang lain. Jadi, proses afiks atau afiksasi sangat penting dan memerlukan ketepatan karena jika salah maka makna dan bentuknya akan menjadi tidak sempurna.

\section{KESIMPULAN}

Berdasarkan hasil analisis dan pembahasan tentang penggunaan afiksasi pembentuk verba dalam karangan deskripsi kelas VII B semester 2 di MTs. Muhammadiyah Lebung Itam Kecamatan Tulung Selapan Kabupaten Ogan Komering Ilir Tahun Pelajaran 2020/2021. Pada temuan afiksasi pembentuk verba terdapat 9 jenis temuan pada karangan deskripsi yang dibuat siswa kelas VII B yaitu, prefiks ter-, prefiks me-prefiks ber-, prefiks $d i$ ,konfiks ke - an, konfiks pe $a n$, sufiks -kan, sufiks $-I$, prefiks per.

Afiksasi yang ditemukan siswa tersebut sudah cukup beragam. Hal ini menunjukkan bahwa siswa cukup memahami penggunaan afiksasi verba tersebut. Afiksasi verba yang digunakan siswa misalnya:

1. Prefiks ter- jika dibubuhkan dengan dasar kata kenal maka akan membentukan dasar terkenal. Prefiks ter- jika jadi maka terjadi

2. Prefiks me- jika nerus maka membentukkan kata -kata menerus. Prefiks me- jika dibubuhkan pada kata dasar 
bakar maka akan membentuk kata melompat.

3. Prefiks ber- jika dibubuhkan henti maka dapat kata bergerak.

4. Prefiks di- jika dibubuhkan buat maka mendapatkan dengan kata dipakai.

5. Konfiks ke -an jika dibubuhkan pada suatu dasar ragam maka dapat membentukkan keragaman.

6. Konfiks pe - an jika dibubukan baik maka dapat membentukan penampilan.

7. Sufiks -kan jika dibubuhkan dapat disampai maka dapat membentukan dengan dapatkan.

8. Sufiks $-i$ jika dibubuhkan datang maka dapat membentukan dengan kata sukai.

Penggunaan prefiks me-, prefiks ber-, prefiks ter-, prefiks di-, konfiks ke-an-. Konfiks pe-an-, supiks $i$-, sufiks kan-, prefiks per-

\section{DAFTAR PUSTAKA}

Abdul, C. (2003). Seputar Tata Bahasa Baku Bahasa Indonesia. Jakarta: PT Pineka Cipta.

Arifin, Z. (2007). Morfologi: Bentuk, Makna \& Fungsi. Gramedia Widiasarana.

Chaer, A. (2016). Tata Bahasa Praktis Bahasa Indonesia, Jakarta: PT. Rineka Cipta.
Fitriani, F. (2019). Analisis Kesalahan Penulisan Kata Pada Karangan Deskripsi Siswa Kelas VIII SMP Negeri 2 Sekayu. Jurnal Pembahsi (Pembelajaran Bahasa Dan Sastra Indonesia), 9(2), 167-178.

Heru, A. (2018). Pengaruh Penggunaan Media Gambar Terhadap Menulis Karangan Deskripsi. Wahana Didaktika: Jurnal Ilmu Kependidikan, 16(1), 29-34.

Kridalaksana, H. (1986). Kelas kata dalam bahasa Indonesia. Gramedia Pustaka Utama. Missriani, M., \& Fitriani, Y. (2020). Upaya Meningkatkan Kemampuan Menulis Deskripsi Siswa Melalui Model Pembelajaran Langsung Di Kelas IV SDN 1 Tanjung Agung Kabupaten Musi Banyuasin. Jurnal Pembahsi (Pembelajaran Bahasa Dan Sastra Indonesia), 10(2), 121-135.

Muhammad, M. H. (2011). Metode penelitian bahasa. Yogyakarta: Ar-Ruzz Media.

Mulae, S. O., \& Sarif, D. (2021). Kekerabatan Bahasa NonAustronesia Di Halmahera Barat (Bahasa Sahu, Waioli, Gamkonora, Ibo, Tobaru, Loloda) Bahasa Ternate Dan Bahasa Tidore. Humano: Jurnal Penelitian, 12(2), 4855. 
Mulyono, I. (2013). Morfologi (Teori

Sejumput dan Problematik

Terapannya). Bandung:

Yrama Widya. 